\title{
PENGARUH HERBISIDA AMINOSIKLOPILAKLOR TERHADAP KETERJADIAN PARTENOKARPI PADA TANAMAN KELAPA SAWIT (Elaeis guineensis Jacq) MENGHASILKAN DAN DAYA KENDALINYA TERHADAP GULMA
}

\author{
Fernando Iskandar Damanik, Nanik Sriyani \& Sugiatno \\ Agroteknologi Fakultas Pertanian Universitas Lampung, \\ Jl. Prof Soemantri Brodjonegoro No. 1 Bandar Lampung 35143 \\ E-mail: nsriyani06@yahoo.co.id Telp.08127907140
}

\begin{abstract}
ABSTRAK
Penelitian bertujuan untuk mengetahui pengaruh herbisida aminosiklopilaklor terhadap keterjadian partenokarpi pada tanaman kelapa sawit menghasilkan dan untuk mengetahui efektivitas herbisida tersebut dalam mengendalikan gulma. Penelitian disusun dengan menggunakan Rancangan Kelompok Teracak Sempurna yang terdiri atas 6 perlakuan yaitu herbisida aminosiklopilaklor dengan dosis 50,100, $200 \mathrm{~g} / \mathrm{ha}$, herbisida pembanding aminopyralid+triklopir 384+216 g/ha, penyiangan mekanis, dan kontrol, dengan 4 ulangan. Homogenitas ragam diuji dengan uji Bartlet, aditivitas data diuji dengan uji Tukey, dan perbedaan nilai tengah diuji dengan Uji Beda Nyata Terkecil (BNT) pada taraf $5 \%$. Hasil penelitian menunjukkan bahwa : (1) Herbisida aminosiklopilaklor dosis 50, 100, dan $200 \mathrm{~g} \mathrm{ha}^{-1}$ dan herbisida pembanding aminopiralid+triklopir 384+216 g $\mathrm{ha}^{-1}$ yang digunakan dalam pengendalian gulma pada pertanaman kelapa sawit menghasilkan belum mampu memberikan informasi yang pasti mengenai partenokarpi pada buah kelapa sawit sampai dengan 12 minggu setelah aplikasi. Hal ini disebabkan tidak semua tanaman kelapa sawit mengeluarkan tandan/bunga baru sawit selama penelitian berlangsung, (2) herbisida aminosiklopilaklor dosis 50,100, dan $200 \mathrm{~g} \mathrm{ha}^{-1}$ mampu mengendalikan pertumbuhan gulma total pada pertanaman kelapa sawit sampai dengan $8 \mathrm{MSA}$, (3) herbisida aminosiklopilaklor dosis 50, 100, $200 \mathrm{~g} \mathrm{ha}^{-1}$ dan aminopiralid +triklopir $384+216 \mathrm{~g} \mathrm{ha}^{-1}$ mampu mengendalikan pertumbuhan gulma daun lebar total hingga $12 \mathrm{MSA}$ dan mampu mengendalikan gulma golongan rumput hingga 8 MSA tetapi tidak mampu mengendalikan pertumbuhan gulma golongan teki, dan (4) herbisida aminosiklopilaklor dosis 50, 100, $200 \mathrm{~g} \mathrm{ha}^{-1} \mathrm{dan}$ aminopiralid+triklopir 384+216 $\mathrm{g} \mathrm{ha}^{-1}$ mampu mengendalikan gulma dominan Cleome rutidospermae hingga $12 \mathrm{MSA}$, Axonopus compressus hingga $8 \mathrm{MSA}$ dan Digitaria ciliaris hingga 4 MSA.
\end{abstract}

Kata Kunci: aminosiklopilaklor, herbisida, partenokarpi, gulma, kelapa sawit menghasilkan.

\section{PENDAHULUAN}

Kelapa sawit (Elaeis) merupakan komoditi unggulan di Indonesia. Menurut Direktorat Jenderal Perkebunan (2011), luas areal perkebunan kelapa sawit di Indonesia tahun 2009 mencapai 7,5 juta hektar dan merupakan perkebunan kelapa sawit yang terluas di dunia. Untuk mempertahankan prestasi tersebut, masih banyak kendala yang harus diatasi dalam budidaya kelapa sawit. Beberapa kendala dalam budidaya kelapa sawit adalah adanya gangguan hama dan penyakit, dan gulma. Menurut Sastrosayono (2006), gulma di perkebunan kelapa sawit harus dikendalikan supaya secara ekonomi tidak berpengaruh terhadap produksi. Adanya gulma di perkebunan kelapa sawit akan merugikan, karena menghambat jalan pekerja, mempersulit pengawasan, gulma menjadi pesaing tanaman kelapa sawit dalam memperoleh air dan unsur hara, serta kemungkinan menjadi inang hama dan penyakit.
Upaya yang dilakukan dalam pengendalian gulma pada perkebunan kelapa sawit salah satunya dengan cara menggunakan herbisida (Sembodo, 2010). Namun demikian, penggunaan herbisida untuk mengendalikan gulma pada pertanaman kelapa sawit haruslah tidak menimbulkan dampak negatif bagi tanaman kelapa sawit itu sendiri.

Berdasarkan penelitian Keong (1987), setelah mengaplikasikan beberapa macam herbisida, didapati bahwa pikloram efektif dalam menyebabkan terjadinya partenokarpi pada buah kelapa sawit. Menurut Pardal (2001), partenokarpi adalah buah yang terbentuk tanpa melalui polinasi dan fertilisasi.

Partenokarpi pada tanaman kelapa sawit merupakan hal yang merugikan, karena kelapa sawit menjadi tidak memiliki inti sawit yang merupakan bagian yang memiliki nilai ekonomis lebih tinggi dibanding CPO (Crude Palm Oil). 
Herbisida dengan merek dagang MAT28 adalah herbisida dengan bahan aktif aminosiklopilaklor. MAT28 dengan cepat diserap oleh daun dan akar dan ditranslokasikan ke daerah meristematik tanaman, herbisida ini merupakan kelompok zat pengatur tumbuh yang memengaruhi keseimbangan hormon auksin (DuPont, 2012).

Aminopiralid adalah herbisida generasi kelompok zat pengatur tumbuh. Herbisida ini terdaftar dengan cara kerja yang menyerupai 2,4-D, klopiralid, triklopir, pikloram dan dikamba. Herbisida ini efektif untuk mengendalikkan daun lebar yang diaplikasikan pascatumbuh (Tu dkk, 2001).

Triklopir adalah herbisida layaknya auksin sintetik. Jenis herbisida yang membunuh gulma target dengan meniru hormon pertumbuhan tanaman auksin (indole acetic acid), dan bila diberikan pada dosis yang efektif, menyebabkan pertumbuhan tanaman tidak terkendali dan tidak terorganisir yang menyebabkan kematian tanaman (Tu dkk, 2001).

Penelitian ini bertujuan untuk mengetahui pengaruh herbisida aminosiklopilaklor dan kombinasi aminopiralid+triklopir terhadap keterjadian partenokarpi pada tanaman kelapa sawit, dan untuk mengetahui efikasi herbisida aminosiklopilaklor dan kombinasi aminopiralid+ triklopir dalam mengendalikan gulma di kebun kelapa sawit.

\section{BAHAN DAN METODE}

Penelitian ini dilaksanakan di kebun milik petani di Kecamatan Natar, Kabupaten Lampung Selatan, dan Laboratorium Gulma Fakultas Pertanian Universitas Lampung dari bulan November 2012 sampai dengan Maret 2013. Alat yang digunakan adalah knapsack sprayer (alat semprot punggung), gelas ukur, ember plastik, kuadratik, meteran, sabit, timbangan, oven, dan alat tulis. Bahan yang digunakan adalah tanaman kelapa sawit menghasilkan, herbisida berbahan aktif aminosiklopilaklor (MAT28 240 SL) dan kombinasi herbisida berbahan aktif aminopiralid+triklopir (GarlonMix EW).

Penelitian ini disusun dalam Rancangan Kelompok Teracak Sempurna (RKTS) dengan 4 ulangan dan enam perlakuan yaitu aminosiklopilaklor pada dosis 50, 100, dan $200 \mathrm{~g} / \mathrm{ha}$; aminopiralid+triklopir 384+216 g/ha; penyiangan mekanis, dan kontrol (tanpa penyiangan). Data yang diperoleh dianalisis dengan sidik ragam, homogenitas data diuji dengan uji Bartlet, sedangkan aditivitas data diuji dengan uji Tukey. Sedangkan untuk membedakan nilai tengah perlakuan digunakan uji beda nyata terkecil (BNT) pada taraf 5\%.
Jumlah tanaman pada masing-masing plot adalah dua tanaman. Areal yang diaplikasikan herbisida adalah piringan kelapa sawit dengan jari-jari 2 meter terluar dari total 3 meter jari-jari. Luas masing-masing piringan adalah 25,12 $\mathrm{m}^{2}$. Aplikasi herbisida dilakukan dengan menggunakan knapsack sprayer dengan nozel warna merah. Volume semprot yang digunakan adalah $600 \mathrm{l} /$ ha.

Pengamatan dilakukan pada 2, 4, 8, dan 12 MSA. Adapun variabel pengamatan yang diamati adalah keterjadian partenokarpi pada kelapa sawit, diamati pula persentase penutupan dan persentase keracunan pada gulma, bobot kering gulma total, bobot kering gulma pergolongan, dan bobot kering gulma dominan.

Pengambilan sampel gulma dilakukan sebanyak 4 kali yaitu pada 2, 4, 8, dan 12 MSA. Gulma diambil dengan menggunakan kuadran berukuran $0,5 \mathrm{~m}$ x 0,5 m sebanyak satu titik pengambilan pada masing-masing tanaman untuk setiap sampel. Gulma yang ada di dalam kuadran kemudian dipotong tepat setinggi permukaan tanah. Gulma yang masih hidup kemudian dipilah menurut spesiesnya kemudian dikeringkan dengan menggunakan oven selama 48 jam pada suhu $80^{\circ} \mathrm{C}$.

Persentase keracunan dan penutupan gulma diamati setiap 2, 4, 8, dan 12 MSA oleh 2 orang pengamat. Pengamatan dilakukan dengan metode visual pada setiap perlakuan, kemudian hasil pengamatan dari dua pengamat dirata-ratakan.

\section{HASIL DAN PEMBAHASAN}

Keterjadian Partenokarpi. Selama pengamatan yang dilakukan pada 2, 4, 8, dan 12 minggu setelah aplikasi tidak ditemukan adanya indikasi partenokarpi pada buah kelapa sawit. Tingkat skoring yang diperoleh selama pengamatan adalah nol. Hal ini diperoleh dari total bunga/buah yang terindikasi partenokarpi dibagi total bunga. Ciri bunga dan buah yang muncul selama pengamatan adalah ciri-ciri buah normal dimana bunga tidak kuncup dan buah tampak berkembang dengan normal. Namun demikian, tidak semua tanaman kelapa sawit menghasilkan bunga/buah. Sehingga belum bisa memberikan informasi yang jelas mengenai keterjadian partenokarpi akibat penggunaan herbisida aminosiklopilaklor. Hanya tanaman kelapa sawit pada perlakuan aminosiklopilaklor 50 dan $100 \mathrm{~g} \mathrm{ha}^{-1}$ dan perlakuan mekanis yang menghasilkan bunga/buah kelapa sawit.

Berdasarkan penelitian Pardal, dkk. (2004), pada proses regenerasi salak pondoh untuk rekayasa buah partenokarpi didapati bahwa dosis yang efektif untuk mendapatkan klon salak pondoh tanpa biji adalah $30 \mathrm{mg}$ 
$1^{1} 2,4 \mathrm{D}+0,5 \mathrm{mg}{ }^{1}$ pikloram setelah bibit salak pondoh diinkubasi selama 16 jam. Bila dibandingkan dengan dosis aminosiklopilaklor pada penelitian ini yaitu sekitar 62,$8 ; 125,6 ; 251,12 \mathrm{mg} 1^{1}$, tetapi pada dosis tersebut tidak didapati gejala partenokarpi. Hal ini mungkin disebabkan tidak semua bahan aktif herbisida yang diaplikasikan pada piringan kelapa sawit dapat terserap oleh kelapa sawit itu sendiri. Selain bahan aktif yang telah diserap oleh gulma, terjadinya pencucian oleh air hujan mengakibatkan aminosiklopilaklor tidak terserap sepenuhnya oleh kelapa sawit, meskipun dosis aminosiklopilaklor pada penelitian ini lebih tinggi dibanding dosis 2,4 D dan pikloram pada penelitian Pardal dkk.

Persen Penutupan Gulma Total. Berdasarkan hasil pengamatan pada 2, 4, 8 dan 12 MSA yang dilakukan secara visual, pada semua taraf dosis herbisida yang diuji mampu menekan pertumbuhan gulma pada petak pecobaan disajikan pada Tabel 1.

Pada 2 MSA persen penutupan gulma total pada semua taraf dosis herbisida yang diuji mampu menekan dibanding dengan kontrol, kecuali pada perlakuan aminosiklopilaklor $100 \mathrm{~g} \mathrm{ha}^{-1}$. Hal ini sejalan dengan pernyataan Moenandir (1990) bahwa respon beberapa jenis tumbuhan yang berbeda pada satu jenis herbisida dengan dosis yang sama akan berbeda pula. Karena letak kegiatan herbisida itu pada masing-masing tumbuhan juga berbeda ataupun lama beradanya herbisida dalam tumbuhan yang berbeda. Kemantapan herbisida dalam tubuh tumbuhan berkaitan dengan penetrasi dan translokasinya untuk mencapai sasaran. Pada 4, 8, dan 12 MSA aplikasi seluruh perlakuan herbisida mampu menekan persentase penutupan gulma total.

Persen Keracunan Gulma Total. Berdasarkan hasil pengamatan pada $2,4,8$, dan 12 MSA yang dilakukan secara visual diperoleh bahwa herbisida aminosiklopilaklor pada semua taraf dosis yang yang diuji maupun herbisida pembanding mampu meracuni gulma pada petak percobaan (Tabel 2). Pengaruh herbisida yang diaplikasikan terhadap gulma telah

Tabel 1. Pengaruh herbisida terhadap penutupan gulma total (\%).

\begin{tabular}{lccccl}
\hline \multicolumn{1}{c}{ Perlakuan } & Dosis $\left(\mathrm{g} \mathrm{ha}^{-1}\right)$ & $2 \mathrm{MSA}$ & $4 \mathrm{MSA}$ & $8 \mathrm{MSA}$ & $12 \mathrm{MSA}$ \\
\hline Aminosiklopilaklor & 50 & $30,6 \mathrm{~b}$ & $31,3 \mathrm{bc}$ & $38,1 \mathrm{~b}$ & $66,9 \mathrm{~b}$ \\
Aminosiklopilaklor & 100 & $38,8 \mathrm{ab}$ & $34,4 \mathrm{~b}$ & $43,1 \mathrm{~b}$ & $63,1 \mathrm{~b}$ \\
Aminosiklopilaklor & 200 & $27,5 \mathrm{~b}$ & $18,8 \mathrm{c}$ & $30,0 \mathrm{~b}$ & $67,5 \mathrm{~b}$ \\
Aminopiralid+Triklopir & $384+216$ & $26,3 \mathrm{~b}$ & $27,5 \mathrm{bc}$ & $40,6 \mathrm{~b}$ & $69,4 \mathrm{~b}$ \\
Mekanis & - & $0,5 \mathrm{c}$ & $3,1 \mathrm{~d}$ & $8,4 \mathrm{c}$ & $21,8 \mathrm{c}$ \\
Kontrol & - & $53,1 \mathrm{a}$ & $66,3 \mathrm{a}$ & $72,5 \mathrm{a}$ & $84,4 \mathrm{a}$ \\
\hline & & 16,0 & 14,9 & 16,5 & 13,1 \\
\hline
\end{tabular}

Keterangan: Nilai tengah pada setiap kolom yang diikuti oleh huruf yang sama tidak berbeda nyata menurut uji BNT pada taraf $5 \%$.

Tabel 2. Pengaruh herbisida terhadap keracunan gulma total.

\begin{tabular}{|c|c|c|c|c|c|c|c|c|c|}
\hline \multirow[b]{2}{*}{ Perlakian } & \multirow[b]{2}{*}{ Dosis (g/ha) } & \multicolumn{2}{|c|}{$2 \mathrm{MSA}$} & \multicolumn{2}{|r|}{$4 \mathrm{MSA}$} & \multicolumn{2}{|c|}{$8 \mathrm{MSA}$} & \multicolumn{2}{|c|}{$12 \mathrm{MBA}$} \\
\hline & & Asli & $\begin{array}{c}\text { tans } \\
\sqrt{(}(\sqrt{x}+0,5))\end{array}$ & Asli & $\begin{array}{c}\text { trans } \\
\left.v\left(v_{x}+0,5\right)\right)\end{array}$ & Asli & $\begin{array}{c}\text { trans } \\
\left.\sqrt{(}\left(v_{x}+0,5\right)\right)\end{array}$ & Asli & $\begin{array}{c}\operatorname{trars} \\
\mathrm{V}(\mathrm{V} \times \mathrm{x}+0,5))\end{array}$ \\
\hline Arrinceiklopilaklor & 50 & 12,50 & $1,41 \mathrm{~d}$ & 14,38 & $1,43 \mathrm{c}$ & 7,50 & $1,33 \mathrm{~b}$ & 1,25 & $1,07 \mathrm{a}$ \\
\hline Arrinosiklopilaklor & 100 & 18,75 & $1,48 \mathrm{c}$ & 10,63 & $1,39 \mathrm{c}$ & 5,25 & $1,28 \mathrm{~b}$ & 1,75 & $1,09 \mathrm{a}$ \\
\hline Arrincesiklopilaklor & 200 & 58,13 & $1,69 \mathrm{a}$ & 53,75 & $1,67 \mathrm{a}$ & 15,00 & $1,44 \mathrm{a}$ & 2,50 & $1,17 \mathrm{a}$ \\
\hline Arriropyralict+Triklopir & $384+216$ & 43,75 & $1,63 \mathrm{~b}$ & 30,63 & $1,56 \mathrm{~b}$ & 15,00 & $1,42 \mathrm{a}$ & 1,50 & $1,09 \mathrm{a}$ \\
\hline Mekanis & & 0,00 & $0,84 \mathrm{e}$ & 0,00 & $0,84 d$ & 0,00 & $0,84 \mathrm{c}$ & $0, \infty$ & $0,84 \mathrm{~b}$ \\
\hline Kontrol & & 0,00 & $0,84 \mathrm{e}$ & 0,00 & $0,84 d$ & 0,00 & $0,84 \mathrm{c}$ & 0,00 & $0,84 \mathrm{~b}$ \\
\hline BNT 0,05 & & & 0,05 & & 0,07 & & 0,07 & & 0,17 \\
\hline
\end{tabular}

Keterangan: Nilai tengah pada setiap kolom yang diikuti oleh huruf yang sama tidak berbeda nyata menurut uji BNT pada taraf $5 \%$. 
terlihat dengan adanya kematian gulma yang disebabkan telah terabsorbsinya herbisida dan ditranslokasikan ke jaringan tumbuhan.

Bobot Kering Gulma Total. Daya kendali herbisida ditunjukkan oleh data bobot kering gulma total pada Tabel 3. Hasil penelitian menunjukkan pada 2 MSA semua perlakuan herbisida mampu mengendalikan gulma total yang terdapat pada petak percobaan. Sedangkan perlakuan dosis tidak menyebabkan bobot kering gulma total antar perlakuan berbeda.

Pada pengamatan 4 MSA semua perlakuan herbisida kecuali aminopiralid +triklopir 384+216 $\mathrm{g} \mathrm{ha}^{-}$ ${ }^{1}$ mampu mengendalikan pertumbuhan gulma. Hal ini dapat dilihat dari bobot kering gulma yang lebih rendah dibandingkan kontrol. Pada 8 MSA perlakuan herbisida pada berbagai taraf dosis dan penyiangan mekanis tidak menunjukkan perbedaan bobot kering, namun masih dapat menekan bobot kering gulma total bila dibandingkan dengan kontrol. Pada 12 MSA perlakuan herbisida dan penyiangan mekanis tidak lagi mampu menekan pertumbuhan gulma total pada setiap petak percobaan.

Bobot kering gulma golongan daun lebar. Selama 12 minggu pengamatan, didapati bahwa gulma golongan daun lebar yang terdapat pada petak percobaan adalah Ageratum conyzoides, Asystasia gangetica, Borreria lattifolia, Calapogonium muconoides, Cleome rutidosperma, Chromolaena odorata, Croton hirtus, Commelina benghalensis, Ipomoea triloba, Mikania micrantha, Mimosa invisa, Oxalys barrelieri, Phorophyllum ruderale, Phyllantus debbilis, Spigelia anthelmia, dan Synedrella nodiflora.

Data pada Tabel 4 menunjukkan bahwa pada 2 dan 4 MSA gulma golongan daun lebar yang terdapat pada petak percobaan mampu dikendalikan oleh perlakuan herbisida 50, 100, dan $200 \mathrm{~g} \mathrm{ha}^{-1}$ maupun herbisida pembanding aminopiralid+triklopir 384+216 g $\mathrm{ha}^{-1}$. Sedangkan perbedaan dosis tidak menyebabkan bobot kering gulma daun lebar antar perlakuan berbeda.

Tabel 3. Pengaruh herbisida terhadap bobot kering gulma total $\left(\mathrm{g} / 0,5 \mathrm{~m}^{2}\right)$.

\begin{tabular}{lcccccc}
\hline \multirow{2}{*}{ Perlakuan } & \multirow{2}{*}{ Dosis $\left(\mathrm{g} \mathrm{ha}^{-1}\right)$} & \multicolumn{2}{c}{2 MSA } & \multirow{2}{*}{4 MSA } & 8 MSA & \multirow{2}{*}{$12 \mathrm{MSA}$} \\
\cline { 3 - 5 } & & Asli & $\operatorname{trans} \sqrt{(\sqrt{\mathrm{x}}+0,5)})$ & & & \\
\hline Aminosiklopilaklor & 50 & 22,96 & $1,49 \mathrm{~b}$ & $10,8 \mathrm{~b}$ & $22,8 \mathrm{~b}$ & $33,5 \mathrm{a}$ \\
Aminosiklopilaklor & 100 & 20,99 & $1,49 \mathrm{~b}$ & $9,7 \mathrm{~b}$ & $15,5 \mathrm{~b}$ & $29,2 \mathrm{a}$ \\
Aminosiklopilaklor & 200 & 17,68 & $1,46 \mathrm{~b}$ & $8,8 \mathrm{~b}$ & $13,2 \mathrm{~b}$ & $33,5 \mathrm{a}$ \\
Aminopiralid+Triklopir & $384+216$ & 15,48 & $1,37 \mathrm{~b}$ & $15,3 \mathrm{ab}$ & $13,4 \mathrm{~b}$ & $29,1 \mathrm{a}$ \\
Mekanis & & 0,00 & $0,84 \mathrm{c}$ & $3,2 \mathrm{c}$ & $11,4 \mathrm{~b}$ & $31,4 \mathrm{a}$ \\
Kontrol & 78,84 & $1,75 \mathrm{a}$ & $25,9 \mathrm{a}$ & $43,1 \mathrm{a}$ & $39,9 \mathrm{a}$ \\
\hline \multicolumn{2}{c}{ BNT 0.05 } & & 0,15 & 12,3 & 13,6 & 12,3 \\
\hline
\end{tabular}

Keterangan: Nilai tengah pada setiap kolom yang diikuti oleh huruf yang sama tidak berbeda nyata menurut uji BNT pada taraf $5 \%$.

Tabel 4. Pengaruh herbisida terhadap bobot kering gulma golongan daun lebar total $\left(\mathrm{g} / 0,5 \mathrm{~m}^{2}\right)$.

\begin{tabular}{|c|c|c|c|c|c|c|}
\hline \multirow{2}{*}{ Perlakuan } & \multirow{2}{*}{ Dosis $\left(\mathrm{g} \mathrm{ha}^{-1}\right)$} & \multicolumn{2}{|r|}{$2 \mathrm{MSA}$} & \multirow{2}{*}{$4 \mathrm{MSA}$} & \multirow{2}{*}{$8 \mathrm{MSA}$} & \multirow{2}{*}{$12 \mathrm{MSA}$} \\
\hline & & Asli & $\operatorname{trans} \sqrt{(\sqrt{x}+0,5))}$ & & & \\
\hline Aminosiklopilaklor & 50 & 0,00 & $0,84 \mathrm{~b}$ & $0,83 \mathrm{~b}$ & $1,07 \mathrm{~b}$ & $3,59 \mathrm{c}$ \\
\hline Aminosiklopilaklor & 100 & 0,00 & $0,84 \mathrm{~b}$ & $0,49 \mathrm{~b}$ & $3,17 \mathrm{ab}$ & $3,48 \mathrm{c}$ \\
\hline Aminosiklopilaklor & 200 & 0,00 & $0,84 \mathrm{~b}$ & $0,85 \mathrm{~b}$ & $1,87 \mathrm{~b}$ & $3,68 \mathrm{c}$ \\
\hline Aminopiralid+Triklopir & $384+216$ & 0,00 & $0,84 \mathrm{~b}$ & $0,72 \mathrm{~b}$ & $0,59 \mathrm{~b}$ & 4,86 bc \\
\hline Mekanis & & 0,00 & $0,84 \mathrm{~b}$ & $1,28 \mathrm{~b}$ & $8,72 \mathrm{a}$ & $16,31 \mathrm{a}$ \\
\hline Kontrol & & 10,07 & $1,36 \mathrm{a}$ & $3,31 \mathrm{a}$ & $4,36 \mathrm{ab}$ & $13,21 \mathrm{ab}$ \\
\hline BNT 0,0 & & & 0,08 & 1,79 & 5,84 & 9,37 \\
\hline
\end{tabular}

Keterangan: Nilai tengah pada setiap kolom yang diikuti oleh huruf yang sama tidak berbeda nyata menurut uji BNT pada taraf $5 \%$. 
Pada 8 MSA bobot kering gulma golongan daun lebar dari berbagai perlakuan tidak berbeda nyata dengan petak kontrol. Hal ini diduga karena pada 8 MSA gulma golongan daun lebar banyak yang tumbuh dan telah mengalami pulih kembali meskipun sebelumnya menunjukkan gejala keracunan bahkan kematian (Moenandir, 1990). Namun demikian, pada 12 MSA gulma golongan daun lebar dapat dikendalikan oleh perlakuan aminosiklopilaklor 50, 100, dan $200 \mathrm{~g} \mathrm{ha}^{-1}$, sementara perlakuan herbisida pembanding aminopiralid+triklopir $384+216 \mathrm{~g} \mathrm{ha}^{-1}$ sudah tidak lagi mampu mengendalikan gulma golongan daun lebar.

Bobot kering gulma golongan rumput. Gulma dari golongan rumput yang terdapat pada petak percobaan antara lain Axonophus compressus, Brachiaria mutica, Cynodon dactylon, Dactylotenium aegyptum, Digitaria ciliaris, Eleusine indica, Echinochloa colona, Eragrostis tenella, Paspalum conjugatum, dan Setaria plicata.

Hasil pengamatan pengaruh herbisida terhadap bobot kering gulma golongan rumput disajikan pada Tabel 5. Data menunjukkan bahwa herbisida amino siklopilaklor dan aminopiralid + triklopir mampu mengendalikan pertumbuhan gulma mulai dari 2,4 , dan 8 MSA demikian pula dengan penyiangan mekanis. Hal ini dapat dilihat dari bobot kering gulma golongan rumput pada seluruh petak percobaan perlakuan herbisida berbeda nyata dengan petak kontrol. Demikian pula dengan perlakuan mekanis dapat mengendalikan gulma golongan rumput. Pada 12 MSA semua perlakuan herbisida maupun mekanis tidak lagi mampu menekan pertumbuhan gulma golongan rumput, hal ini dapat dilihat dari nilai bobot kering gulma pada petak perlakuan herbisida yang tidak berbeda nyata dengan kontrol. Secara harfiah herbisida aminosiklopilaklor merupakan herbisida selektif untuk mengendalikan gulma golongan daun lebar (DuPont, 2012), namun peningkatan dosis dapat menyebabkan herbisida ini menjadi nonselektif. Hal ini sejalan dengan pendapat Sembodo (2010), dimana jumlah atau dosis herbisida yang diaplikasikan dan dapat diserap menentukan selektifitas herbisida tersebut dan semua jenis herbisida menjadi tidak selektif apabila diaplikasikan dalam jumlah tinggi.

Bobot kering gulma golongan teki. Gulma dari golongan teki yang terdapat pada petak percobaan adalah Cyperus rotundus, Cyperus killingia, dan Fimbristylis spp. Tabel 6 menunjukkan bahwa herbisida aminosiklopilaklor dan aminopiralid+triklopir tidak mampu mengendalikan pertumbuhan gulma golongan teki pada berbagai taraf dosis herbisida yang diuji maupun penyiangan mekanis. Hal ini ditunjukkan dengan bobot kering gulma golongan teki pada berbagai perlakuan tidak berbeda nyata dengan petak kontrol, baik pada 2, 4, 8, dan 12 MSA.

\section{KESIMPULAN}

Hasil penelitian menunjukkan bahwa (1) Herbisida aminosiklopilaklor dosis 50, 100, dan $200 \mathrm{~g} \mathrm{ha}^{-1}$ dan herbisida pembanding aminopiralid+triklopir 384+216 g ha $^{-1}$ yang digunakan dalam pengendalian gulma pada pertanaman kelapa sawit menghasilkan belum mampu memberikan informasi yang pasti mengenai partenokarpi pada kelapa sawit sampai dengan 12 minggu setelah aplikasi. Hal ini disebabkan tidak semua tanaman kelapa

Tabel 5. Pengaruh herbisida terhadap bobot kering gulma golongan rumput $\left(\mathrm{g} / 0,5 \mathrm{~m}^{2}\right)$.

\begin{tabular}{|c|c|c|c|c|c|c|}
\hline \multirow{2}{*}{ Perlakuan } & \multirow{2}{*}{ Dosis $\left(\mathrm{g} \mathrm{ha}^{-1}\right)$} & \multicolumn{2}{|r|}{$2 \mathrm{MSA}$} & \multirow{2}{*}{4 MSA } & \multirow{2}{*}{$8 \mathrm{MSA}$} & \multirow{2}{*}{$12 \mathrm{MSA}$} \\
\hline & & Asli & $\operatorname{trans} \sqrt{(\sqrt{\mathrm{x}}+0,5))}$ & & & \\
\hline Aminosiklopilaklor & 50 & 22,33 & $1,49 \mathrm{~b}$ & $10,0 \mathrm{bc}$ & $20,8 \mathrm{~b}$ & $27,9 \mathrm{ab}$ \\
\hline Aminosiklopilaklor & 100 & 20,99 & $1,49 \mathrm{~b}$ & $9,1 \mathrm{bc}$ & $11,5 \mathrm{bc}$ & $25,7 \mathrm{ab}$ \\
\hline Aminosiklopilaklor & 200 & 17,68 & $1,46 \mathrm{~b}$ & $7,6 \mathrm{bc}$ & $10,3 \mathrm{bc}$ & $29,7 \mathrm{a}$ \\
\hline Aminopiralid+Triklopir & $384+216$ & 15,48 & $1,37 \mathrm{~b}$ & $13,2 \mathrm{ab}$ & $12,8 \mathrm{bc}$ & $24,2 \mathrm{ab}$ \\
\hline Mekanis & & 0,00 & $0,84 \mathrm{c}$ & $1,7 \mathrm{c}$ & $2,0 \mathrm{c}$ & $12,4 \mathrm{~b}$ \\
\hline Kontrol & & 68,77 & $1,72 \mathrm{a}$ & $22,5 \mathrm{a}$ & $37,8 \mathrm{a}$ & $26,1 \mathrm{ab}$ \\
\hline BNT 0,0 & & & 0,15 & 10,4 & 12,2 & 17,1 \\
\hline
\end{tabular}

Keterangan: Nilai tengah pada setiap kolom yang diikuti oleh huruf yang sama tidak berbeda nyata menurut uji BNT pada taraf $5 \%$. 
Tabel 6. Pengaruh herbisida terhadap bobot kering gulma golongan teki $\left(\mathrm{g} / 0,5 \mathrm{~m}^{2}\right)$

\begin{tabular}{lcccccccc}
\hline \multirow{2}{*}{ Perlakuan } & \multirow{2}{*}{$\begin{array}{c}\text { Dosis } \\
\left(\mathrm{g} \mathrm{ha}^{-1}\right)\end{array}$} & \multicolumn{2}{c}{2 MSA } & \multicolumn{2}{c}{4 MSA } & 8 MSA & \multicolumn{2}{c}{$12 \mathrm{MSA}$} \\
\cline { 3 - 9 } & & Asli & $\begin{array}{c}\text { trans } \\
\sqrt{(\sqrt{\mathrm{x}}+0,5))}\end{array}$ & Asli & $\begin{array}{c}\text { trans } \\
\sqrt{(\sqrt{\mathrm{x}}+0,5))}\end{array}$ & Asli & Asli & $\begin{array}{c}\text { trans } \\
\sqrt{(\sqrt{\mathrm{x}}+0,5))}\end{array}$ \\
\hline Aminosiklopilaklor & 50 & 0,63 & $0,93 \mathrm{a}$ & 0 & $0,84 \mathrm{a}$ & $0,96 \mathrm{a}$ & 2 & $1,04 \mathrm{ab}$ \\
Aminosiklopilaklor & 100 & 0 & $0,84 \mathrm{a}$ & 0,13 & $0,89 \mathrm{a}$ & $0,85 \mathrm{a}$ & 0 & $0,84 \mathrm{~b}$ \\
Aminosiklopilaklor & 200 & 0 & $0,84 \mathrm{a}$ & 0,36 & $0,92 \mathrm{a}$ & $1,02 \mathrm{a}$ & 0,16 & $0,92 \mathrm{ab}$ \\
Aminopyralid+Triklopir & 600 & 0 & $0,84 \mathrm{a}$ & 1,39 & $0,96 \mathrm{a}$ & $0,08 \mathrm{a}$ & 0 & $0,84 \mathrm{~b}$ \\
Mekanis & & 0 & $0,84 \mathrm{a}$ & 0,26 & $0,91 \mathrm{a}$ & $0,76 \mathrm{a}$ & 2,75 & $1,12 \mathrm{a}$ \\
Kontrol & & 0 & $0,84 \mathrm{a}$ & 0,23 & $0,94 \mathrm{a}$ & $0,94 \mathrm{a}$ & 0,53 & $0,98 \mathrm{ab}$ \\
\hline \multicolumn{1}{c}{ BNT 0,05 } & & & 0,11 & & 0,22 & 1,92 & & 0,25 \\
\hline
\end{tabular}

Keterangan: Nilai tengah pada setiap kolom yang diikuti oleh huruf yang sama tidak berbeda nyata menurut uji BNT pada taraf $5 \%$.

sawit mengeluarkan tandan buah/bunga selama penelitian berlangsung, (2) herbisida aminosiklopilaklor dosis 50,100, dan $200 \mathrm{~g} \mathrm{ha}^{-1}$ mampu mengendalikan pertumbuhan gulma total pada pertanaman kelapa sawit sampai dengan 8 MSA, (3) herbisida aminosiklopilaklor dosis 50, 100, $200 \mathrm{~g} \mathrm{ha}^{-1}$ dan aminopiralid+triklopir $384+216 \mathrm{~g} \mathrm{ha}^{-1}$ mampu mengendalikan pertumbuhan gulma daun lebar total hingga 12 MSA dan mampu mengendalikan gulma golongan rumput hingga $8 \mathrm{MSA}$, tetapi tidak mampu mengendalikan gulma golongan teki, dan (4) herbisida aminosiklopilaklor dosis 50, 100, 200 $\mathrm{g} \mathrm{ha}^{-1}$ dan aminopiralid+ triklopir $384+216 \mathrm{~g} \mathrm{ha}^{-1}$ mampu mengendalikan gulma dominan Cleome rutidospermae hingga 12 MSA, Axonopus compressus hingga 8 MSA dan Digitaria ciliaris hingga 4 MSA.

\section{DAFTAR PUSTAKA}

Direktorat Jenderal Perkebunan. 2011. Lintasan 30 Tahun Pengembangan Kelapa Sawit di Indonesia : http://ditjenbun.deptan.go.id/ tahunanbun/tahunan (diakses pada tanggal 7 Oktober 2012).

DuPont. 2012. Technical Bulletin of Aminocyclophyrachlor (Tutorial DPX MAT 28). DuPont Agricultural Bulletin, 8 hal.

Keong, W. C. 1987. Development of parthenocarpic fruits in oil palm (Elaeis guineensis Jacq.) due to application of herbicides. Journal Planter 1987 Vol. 63 No. 732 pp. 90-95.

Moenandir, J. 1990. Fisiologi Herbisida. Jakarta. Rajawali. 143 hal.
Pardal, J. S. 2001. Pembentukan buah partenokarpi melalui rekayasa genetika. Balai Penelitian Bioteknologi Tanaman Pangan, Bogor. Buletin AgroBio 4(2):45-49.

Pardal, J. S., M. Ika, E.G. Lestari, dan Slamet. 2004. Regenerasi Tanaman dan Transformasi Genetic Salak Pondoh untuk Rekayasa Partenokarpi. Balai Besar Penelitian dan Pengembangan Bioteknologi dan Sumber Daya Genetik Pertanian. Jurnal Bioteknologi Pertanian, Vol 9, No. 2, 2004. pp 49-55.

Sastrosayono, S. 2006. Budidaya Kelapa Sawit. Agromedia Pustaka. Yogyakarta. 66 hal.

Sembodo, D. R. J. 2010. Gulma dan Pengelolaannya. Graha Ilmu. Yogyakarta. 168 hal.

Tu, M., C. Hurd, J.M. Randall. 2001. "Weed Control Methods Handbook: Tools \& Techniques for Use in Natural Areas". U.S. Government Documents (Utah Regional Depository). Paper 533. http://digitalcommons.usu.edu/govdocs/533 (diakses pada tanggal 15 juni 2013). 